\title{
Displaced Type II Odontoid Fracture with Congenital Proximal Cervical Spine Anomalies Treated with Noninvasive Halo Vest: Clinical, Functional And Radiological Outcome. A Case Report.
}

Mustafa Eltayeb ( $\nabla$ mustafa_elsadig@yahoo.com )

University of Khartoum

Research article

Keywords: Proximal cervical spine anomalies, non invasıve halo, Type II odontoid fracture

Posted Date: January 2nd, 2020

DOI: https://doi.org/10.21203/rs.2.19840/v1

License: (9) This work is licensed under a Creative Commons Attribution 4.0 International License.

Read Full License 


\section{Abstract}

Study Design: A retrospective study. Objective: To evaluate the clinical, functional and radiological outcomes of noninvasive halo in the treatment of a displaced type 2 odontoid fracture in a patient with congenital proximal cervical spine anomalies.

Case report: A 42 years old male applied to our institution 2 years ago with the complaint of neck pain after falling down from a 10 meters height. The patient was neurologically intact and diagnosed as displaced type 2 odontoid fracture. The patient had congenital elongated odontoid process and posterior fusion of $\mathrm{C} 2-\mathrm{C} 3$. Against medical advice the patient refused surgery and also refused the invasive halo vest. Noninvasive halo vest was applied for 8 weeks. The patient was followed up clinically radiologically and functionally. Results: Neurological status remained same till the last follow up which was ASIA E. VAS score was 9 initially and it was improved up to 2 during the last follow up. The patient had normal range of motion during the last follow up. Reduction of the fracture was maintained and fracture healed after 8 weeks confirmed by X-ray. Initially Patient had transient facial edema subsided by day 4, pressure ulcer which responded to dressing, also the patient had difficulties to chew hard food and self-hygiene.

Conclusion : Noninvasive halo can be a salvage option to reduce type 2 displaced odontoid fractures. Maintaining range of motion of cervical spine especially in young patient with proximal cervical spine congenital anomalies. In addition it is more Cost effective than surgery.

\section{Introduction}

Fractures of C2 account for approximately $17-25 \%$ of acute cervical fractures ${ }^{1,2}$. Odontoid fracture accounts for up to $20 \%$ of all cervical spine injuries and most often occurs due to high-speed motor vehicle collisions ${ }^{3,4}$. Type II odontoid fracture occurs at the dens-vertebral body junction ${ }^{5}$. Treatment strategies for odontoid fractures are based on fracture type, the degree of initial dens displacement, the angulation of the dens with respect to the body of $\mathrm{C} 2$, and the age of the patient. The nonunion rate for odontoid fractures is between $4 \%$ and $64 \%$ depending on the fracture site and method of treatment $6,7,8$.

The optimal treatment of Type II fracture remains debated. Varying severity of associated ligament injury, instability, and comorbidity confound treatment options. ${ }^{9,10}$ These options include external fixation with a halo-vest ${ }^{11}$ or collar ${ }^{12}$ or internal fixation either anteriorly with an odontoid screw ${ }^{13,14}$ or posteriorly with the $\mathrm{C} 1-\mathrm{C} 2$ fusion with polyaxial screw fixation ${ }^{15}$ or transarticular screws ${ }^{16}$ or wiring ${ }^{17}$. High nonunion rates and complications associated with external fixation have been reported ${ }^{18-22}$.

Risk factors for nonunion include inadequate immobilization, fracture comminution, delayed diagnosis, elderly age, posterior fracture displacement, or excessive fracture displacement regardless of direction. Internal fixation is associated with higher union rates ${ }^{23,24}$. Each treatment option for Type II dens fracture has advantages and associated disadvantages. ${ }^{25}$ Among external fixation techniques, the halo-vest provides the greatest neck immobilization as compared with other orthoses ${ }^{26,27}$. 
The aim of this case report was to evaluate using of noninvasive halo clinically, functionally and radiologically in treatment of displaced type 2 odontoid fracture. To date, no study evaluate using of noninvasive halo in treatment of displaced type 2 odontoid fracture with proximal cervical anomalies. This report may change the current practice by considering noninvasive halo as valid option to chive reduction and union of displaced type 2 odontoid fracture in young patients, especially whom with congenital proximal cervical anomalies and to avoid morbidity of surgery.

\section{Case Report}

The study was approved by the institutional research review board. Verbal and written consent was taken from the patient.

A previously health 42 years old male after falling from a 10 meters height, applied to trauma and emergency department with the complaint of neck pain. The patient was found to be neurologically intact ASIA E (American spine injury association score), however cervical region was tender with palpation and neck range of motion (ROM) was severely limited.

Radiological evaluation including X-ray figure (1), CT (Computerized tomography) scan figure (2) and MRI (Magnetic Resonance imaging) figure (3) revealed displaced Type 2 odontoid fracture with $40^{\circ}$ anterior angulation, $30 \%$ anterior translation, with congenital elongated odontoid process and posterior fusion of C2-C3. VAS (Visual Analogue Scale) was noted as 9. There was no other associated injuries. CT angiography was requested as vascular anomalies was highly suspected and surgical intervention or halo-vest application was planned. However, the patient refused both surgery and invasive halo vest.

Noninvasive halo was applied under fluoroscopy without anesthesia in the same day immediately after trauma, gradual reduction of odontoid fracture was done gently and the patient asked to notice if any pain, numbness or weakness during procedure, anatomical reduction was achieved and was confirmed radiologically figure (4). Patient had transient facial edema which subsided by day 4 , and pressure ulceration figure (5), which responded to wet dressing. Also the patient had difficulties to chew hard food and self-hygiene.

The patient was followed up weekly clinically and radiologically, with noninvasive halo for 8 weeks and then noninvasive halo was removed figure (6). After the removal of noninvasive halo, VAS score was found to be 4 and neck ROM was restricted figure (7). The patient was sent for physical therapy for 4 weeks. After four weeks ROM improved. Cervical flexion was $40^{\circ}$, extension was $60^{\circ}$, right and left lateral flexion were $35^{\circ}$, right and left rotations were $55^{\circ}$ and $60^{\circ}$ respectively. The patient was followed up for 2 years. VAS was 2 and neck ROM were: flexion $45^{\circ}$, extension $70^{\circ}$, right and left rotation $70^{\circ}$, right and left lateral flexion $40^{\circ}$ During the last follow up. There was no neurological deficit. According to the Smiley-Webster Scale ${ }^{31}$ Table (1), patient achieved clinically good outcomes during the last follow up. The union of odontoid fracture was confirmed by X-ray after 8 weeks of noninvasive halo. During the last follow up there was a loss of correction as $10^{\circ}$ anterior angulation 


\section{Discussion}

The optimal treatment of Type II fracture remains controversial. ${ }^{9,10}$ Each treatment option for Type II odontoid fracture has advantages and disadvantages. ${ }^{25}$ Although High nonunion rate associated with external fixation have been reported, ${ }^{18-22}$ surgical treatment of type 2 odontoid fracture is associated with morbidity and mortality rates between $2 \%$ and $4 \%$. Specific complications for posterior approach include: vertebral artery injury and new onset neurological deficits. In this case report vascular injury was highly considered as higher risk due to possibility of vascular anomalies, although CT angiography was not done. $\mathrm{C} 1$ to $\mathrm{C} 2$ fusion also causes the loss of atlantoaxial movement, rendering the patient unable to rotate his or her head. Surgical interventions such as anterior odontoid screw fixation can preserve atlantoaxial motion, but it is technically demanding and may encountered with failure despite healing rate of $90 \%$ for type II fractures. ${ }^{28,29}$ The major complications of this approach are neural or vessel injury, esophageal and pharyngeal perforation, and airway obstruction. The vulnerable structures include the glossopharyngeal and hypoglossal nerves ${ }^{32}$. Regarding conservative management, among external fixation techniques, the halo-vest provides the greatest neck immobilization as compared with other orthoses and there is no biomechanical differences between variant types of halo vest ${ }^{26,27}$.

To date, no study evaluate treatment of displaced type 2 odontoid fracture with proximal cervical anomalies. Although Clark and White ${ }^{30}$ documented a $68 \%$ healing rate and mean period for bone healing was 20.2 weeks for type 2 dens fracture treated by halo vest. In this case report the odontoid fracture was healed after 8 weeks, however we cannot compare two result as it was one case and there are a lot of confounding factors not analyzed in this case report which include: patient age $>40$ years, fracture displacements $>5 \mathrm{~mm}$, posteriorly displaced fractures $>$ anterior displaced fractures, osteoporosis and in patients with neurological deficits. ${ }^{35}$. In this case report odontoid fracture was healed with $10^{0}$ anterior angulation that may be due to frequent adjustment of non-invasive halo vest to allow dressing for pressure ulcer and reliving the patient stretching discomfort. The patient cervical ROM (flexion $45^{\circ}$, extension $70^{\circ}$, right and left rotation $70^{\circ}$, right and left lateral flexion $40^{\circ}$ ) was achieved during the last follow up, despite initial limitation which was present after immediate removal of noninvasive halo. ROM limitation may be due to stiffness of neck muscles after a long period of immobilization. However ROM was found to be improved during the last follow up. Conservative treatment was found to be superior to surgical fusion of $\mathrm{C} 1-\mathrm{C} 2$ head in terms of preserving movement of cervical rotation. Anterior odontoid screw could be inserted in order to preserve atlanto-axial motion, however in our case this technique was not possible to be performed due to congenital anatomical distortion of dens axis which almost need vertical inclination for trajectory of anterior screw. Using of Noninvasive halo in treatment of displaced odontoid fracture is more cost effective than surgery and invasive halo vest, as there is a significant difference in cost the price of the noninvasive halo is less than $40 \%$ that of invasive halo vest ${ }^{36}$.

In this case report the Patient had transient facial edema subsided by day 4, pressure ulcer which was responded to dressing, self-hygiene and chewing hard food difficulties. Also the patient was complaining of discomfort over all 8 weeks period. On the other hand complications of invasive halo vest 
immobilization are patient discomfort ${ }^{33}$ pin-site infection, osteomyelitis, nerve injury, Dural penetration and CSF leakage, intracranial abscesses, dysphagia, pin-site scar formation, restriction of respiratory function, and loss of reduction. ${ }^{19,33,34}$.

Limitation:

Study design was retrospective case report and Short term follow up. It was evaluated only anterior displacement of type 2 odontoid fracture.

\section{Conclusion}

Non-invasive hallo vest can be a salvage option to reduce, to maintain reduction and to achieve solid union of type 2 displaced odontoid fracture without neurological deficits. Maintaining range of rotatory motion of cervical spine especially in young patient with proximal cervical spine congenital anomalies. It is more cost effective than surgery and invasive halo vest. Higher level prospective studies are needed to support this hypothesis.

\section{List Of Abbreviations}

\begin{tabular}{|l|l|}
\hline ASIA & American spine injury association score \\
\hline ROM & range of motion \\
\hline CT scan & Computerized tomography scan \\
\hline MRI & Magnetic Resonance imaging \\
\hline VAS & Visual Analogue Scale \\
\hline
\end{tabular}

\section{Declarations}

-Ethics approval and consent to participate:

The study was approved by the institutional research review board. Verbal and written consent was taken from the patient.

-Consent for publication:

Verbal and written (BioMed Central form) consents for publication was taken from the patient.

\section{-Availability of data and material:}

The datasets supporting the conclusions of this article are available in the PubMed web site. 


\section{-Competing interests:}

I have no competing of interests.

\section{-Funding:}

No fund was received.

\section{-Authors' contributions:}

There is no Authors' contributions

\section{-Acknowledgements:}

I thank the patient for his agreement to publish this case report and sharing of all data including his pictures. Also I thank my family, teachers and any one has white hand impact on my life.

\section{References}

1.Denaro L, Longo UG, Di Martino A, Denaro V. Cervical spine traumas. In:Denaro L, D'Avella D, Denaro V, editors. Pitfalls in cervical spine surgery. Berlin, Heidelberg: Springer-Verlag; 2010. p. 175-91 [chapter 12].

2. Levine AM, Edwards CC. The management of traumatic spondylolisthesis of the axis. J Bone Joint Surg Am 1985;67:217-26.

3. Greene KA, Dickman CA, Marciano FF, et al. Acute axis fractures. Analysisof management and outcome in 340 consecutive cases. Spine 1997;22:1843-52.

4. Schatzker J, Rorabeck $\mathrm{CH}$, Waddell JP. Fractures of the dens (odontoid Halo-Vest and Dens Screw Fixation .Ivancic et al 489 process). An analysis of thirty-seven cases. J Bone Joint Surg Br 1971;53:392-405.

5. Anderson LD, D'alonzo RT. Fractures of the odontoid process of the axis. J Bone Joint Surg Am 1974;56:1663-74.

6. Majercik S, Tashjian RZ, Biff WL, Harrington DT, Cioffi WG : Halo vest immobilization in the elderly : a death sentence? J Trauma 59 : 350-356; discussion 356-358, 2005.

7. SchweigelJF : Management of the fractured odontoid with halo-thoracic bracing. Spine (Phila Pa 1976) $12: 838-839,1987$.

8. Tashjian RZ, Majercik S, Biff WL, Palumbo MA, CioffiWG : Halo-vest immobilization increases early morbidity and mortality in elderly odontoid fractures. J Trauma 60 : 199-203, 2006.

9. Vieweg U, Schultheiss R. A review of halo vest treatment of upper cervical spine injuries. Arch Orthop Trauma Surg 2001;121:50-5.

10. Rockswold GL, Bergman TA, Ford SE. Halo immobilization and surgical fusion: relative indications and effectiveness in the treatment of 140 cervical spine injuries. J Trauma 1990;30:893-8. 
11. Ziai WC, Hurlbert RJ. A six year review of odontoid fractures: the emerging role of surgical intervention. Can J NeurolSci 2000;27:297-301.

12. Dunn ME, Seljeskog EL. Experience in the management of odontoid process injuries: an analysis of 128 cases. Neurosurgery 1986;18:306-10.

13. Bohler J. Anterior stabilization for acute fractures and non-unions of the dens. J Bone Joint Surg Am 1982;64:18-27.

14. Apfelbaum RI, Lonser RR, Veres R, et al. Direct anterior screw fixation forrecent and remote odontoid fractures. J Neurosurg 2000;93:227-36.

15. Harms J, Melcher RP. Posterior C1-C2 fusion with polyaxial screw and rod fixation. Spine 2001;26:2467-71.

16. Jeanneret B, Magerl F. Primary posterior fusion C1/2 in odontoid fractures: indications, technique, and results of transarticular screw fixation. J Spinal Disord 1992;5:464-75.

17. Brooks AL, Jenkins EB. Atlanto-axial arthrodesis by the wedge compression method. J Bone Joint Surg Am 1978;60:279-84.

18. Frangen TM, Zilkens C, Muhr G, et al. Odontoid fractures in the elderly:dorsal C1/C2 fusion is superior to halo-vest immobilization. J Trauma 2007;63:83-9.

19. Glaser JA, Whitehill R, Stamp WG, et al. Complications associated with the halo-vest. A review of 245 cases. J Neurosurg 1986;65:762-9.

20. Tashjian RZ, Majercik S, Biff WL, et al. Halo-vest immobilization increases early morbidity and mortality in elderly odontoid fractures. J Trauma 2006; 60:199-203.

21. Majercik S, Tashjian RZ, Biff WL, et al. Halo vest immobilization in the elderly: a death sentence? J Trauma 2005;59:350-6; discussion 6-8.

22. Kim DH, Vaccaro AR, Affonso J, et al. Early predictive value of supine and upright X-ray films of odontoid fractures treated with halo-vest immobilization. Spine J 2008;8:612-8.

23. Maiman DJ, Larson SJ. Management of odontoid fractures. Neurosurgery1982;11:820.

24. Verheggen R, Jansen J. Fractures of the odontoid process: analysis of the functional results after surgery. Eur Spine J 1994;3:146-50.

25. Maak TG, Grauer JN. The contemporary treatment of odontoid injuries.Spine 2006;31:S53-60; discussion S1.

26. Johnson RM, Owen JR, Hart DL, et al. Cervical orthoses: a guide to their selection and use. ClinOrthopRelat Res 1981:34-45.

27. Johnson RM, Hart DL, Simmons EF, et al. Cervical orthoses. A study comparing their effectiveness in restricting cervical motion in normal subjects. J Bone Joint Surg Am 1977;59:332-9.

28. Jenkins JD, Coric D, Branch CL Jr : A clinical comparison of one- and two-screw odontoid fixation. J Neurosurg $89: 366-370,1998$

29. Lee SH, Sung JK :screw : The first Anterior odontoid fixation using a 4.5-mm Herbert report of 20 consecutive cases with odontoid fracture. Surg Neurol 66 : 361-366; discussion 366, 2006. 
30. Clark CR, White AA, 3rd : Fractures of the dens. A multicenter study. J Bone Joint.

31. Webster, F, and Smiley, D.(1957) : Evaluation of an operative series of lumbar disc herniation. J Bone Joint surg. 39-A,688.

32. Lee SH, Sung JK: Anterior odontoid fixation using a 4.5-mm Herbert screw: the first report of 20 consecutive cases with odontoid fracture. Surg Neurol 66:361-366, 2006

33. Garfin SR, Botte MJ, Waters RL, Nickel VL: Complications in the use of the halo fixation device. J Bone Joint Surg Am 68:320-325, 1986

34. Lind B, Nordwall A, Sihlbom H: Odontoid fractures treated with halo-vest. Spine 12:173-177, 1987

35. Harrop JS, Vaccaro A, Przybylski GJ: Acute respiratory compromise associated with flexed cervical traction after $\mathrm{C} 2$ fractures. Spine 26:E50-E54, 2001

36. Sawers A1, DiPaola CP, Rechtine GR 2nd. Suitability of the noninvasive halo for cervical spine injuries: a retrospective analysis of outcomes .Spine J. 2009 Mar;9(3):216-20. doi: 10.1016/j.spinee.2008.03.004. Epub 2008 May 20.

\section{Table}

Table 1. Smiley-Webster scale used to assess clinical outcome. ${ }^{31}$

\begin{tabular}{|l|l|}
\hline score & description \\
\hline excellent & $\begin{array}{l}\text { Patient returned to full-time work/activity as before onset of symptoms; no pain medication } \\
\text { required }\end{array}$ \\
\hline good & Patient returned to full-time work/activity; occasional use of pain medication \\
\hline fair & $\begin{array}{l}\text { Patient not able to return to former level of work/activity; occasional pain } \\
\text { medication; improvedoverpreoperativestatus }\end{array}$ \\
\hline poor & $\begin{array}{l}\text { Patient not able to return to work/former activity level; regular use of pain } \\
\text { medication }\end{array}$ \\
\hline
\end{tabular}

\section{Figures}




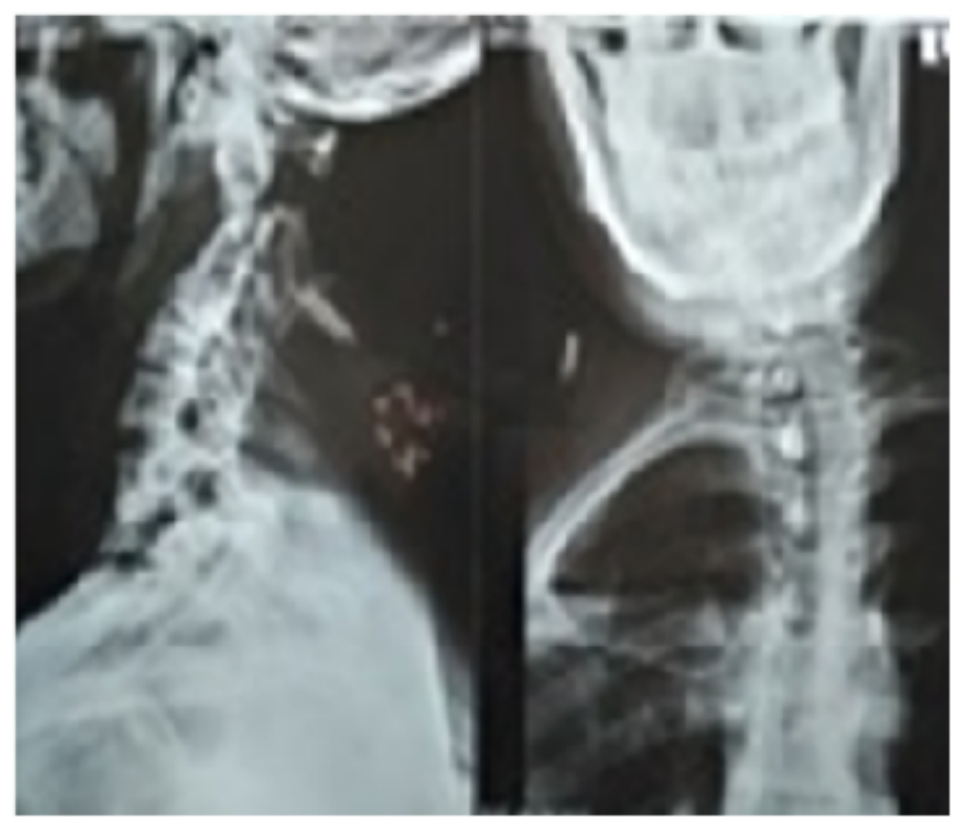

\section{Figure 1}

AP and L cervical X-RAY reveled displaced odontoid fracture

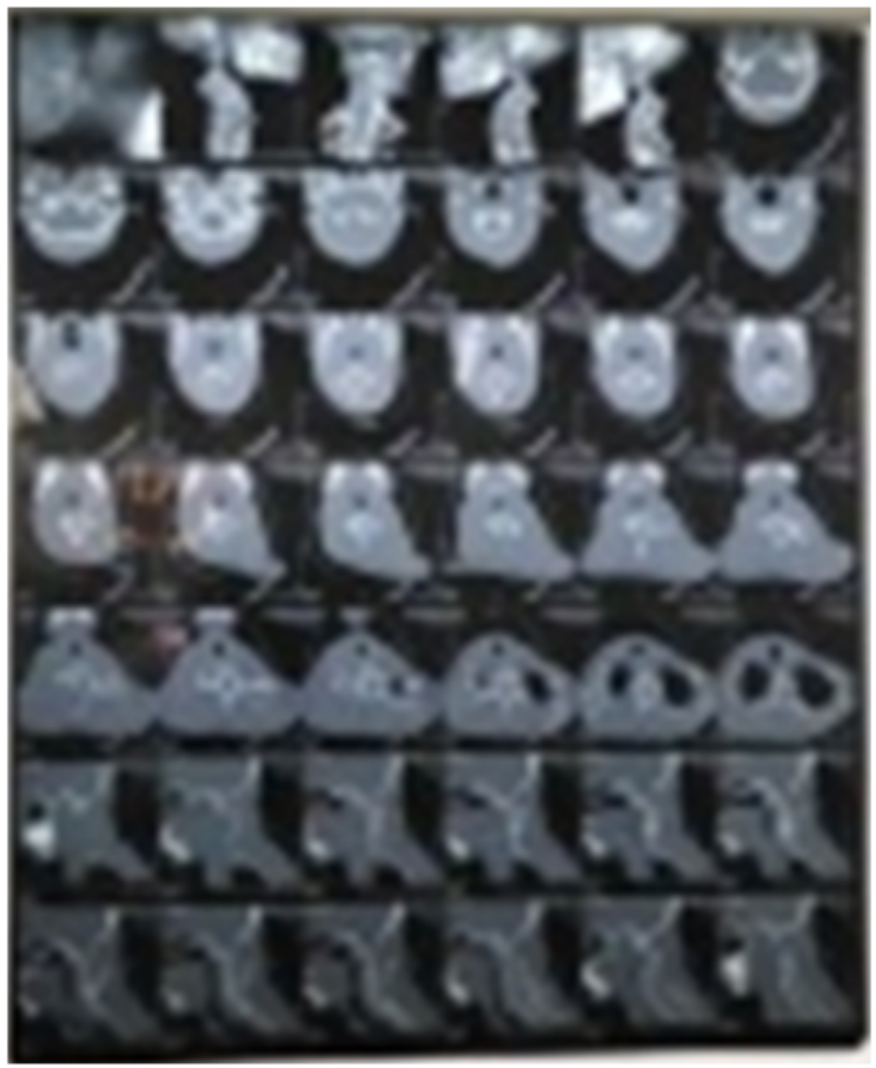

Figure 2

cervical CT scan revealed displaced odontoid fracture with congenital elongated odontoid and C2-C3 fusion. 


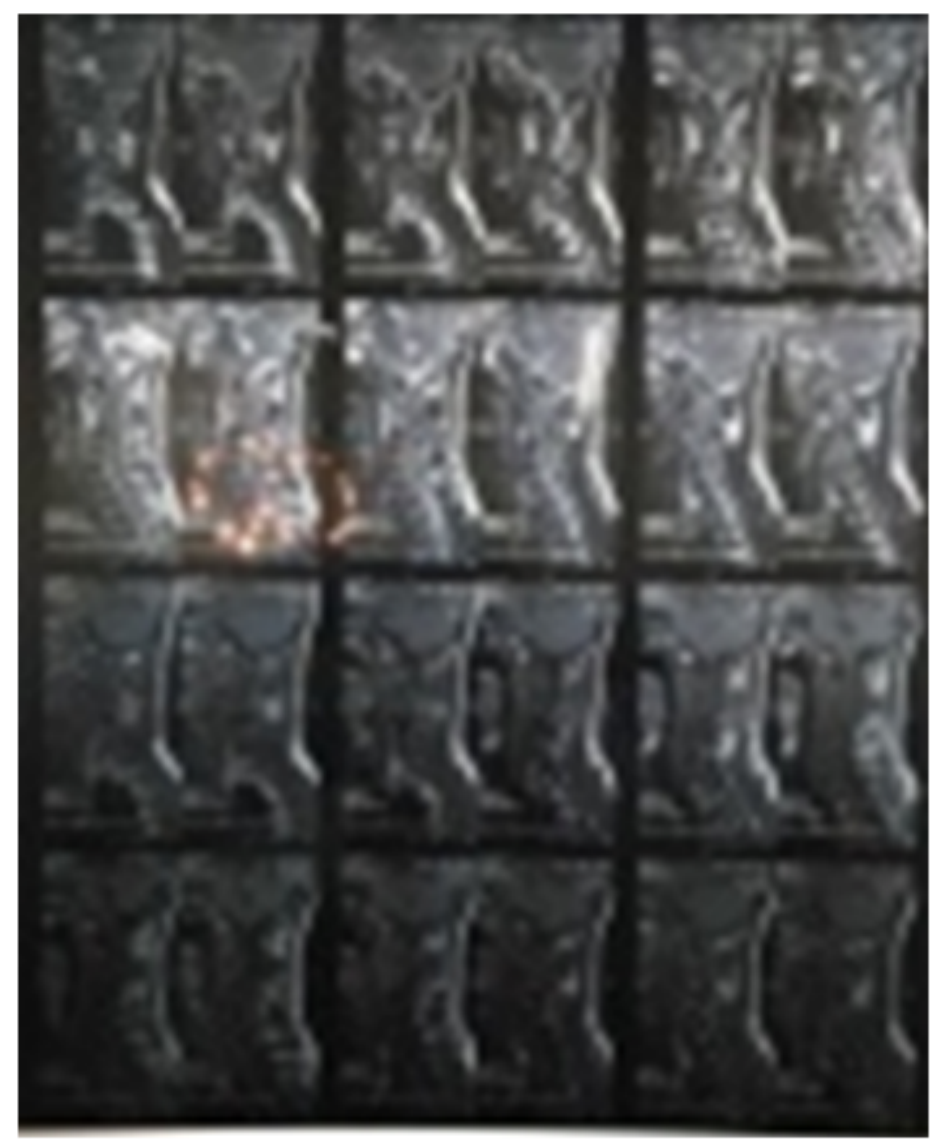

Figure 3

cervical MRI revealed displaced odontoid fracture 


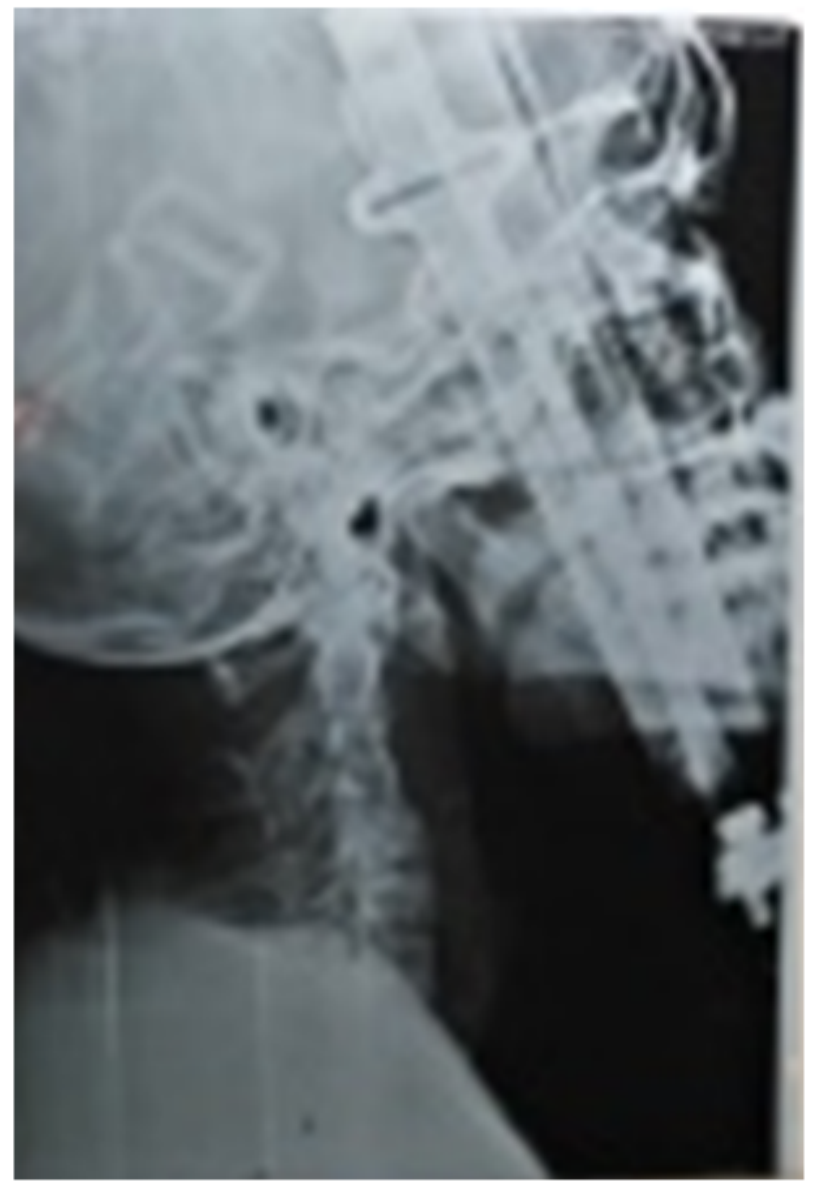

Figure 4

cervical lateral x-ray after application of noninvasive halo reveled reduction of odontoid fracture. 


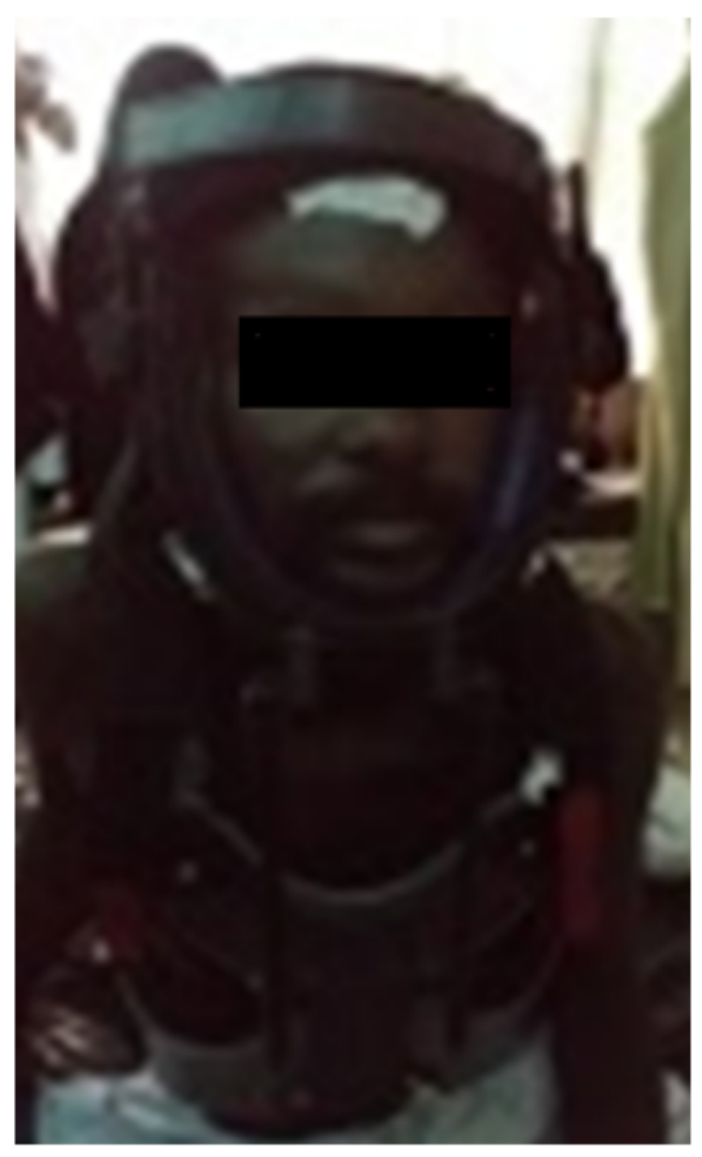

Figure 5

showed the patient 2 weeks after application of noninvasive halo with pressure ulcer.

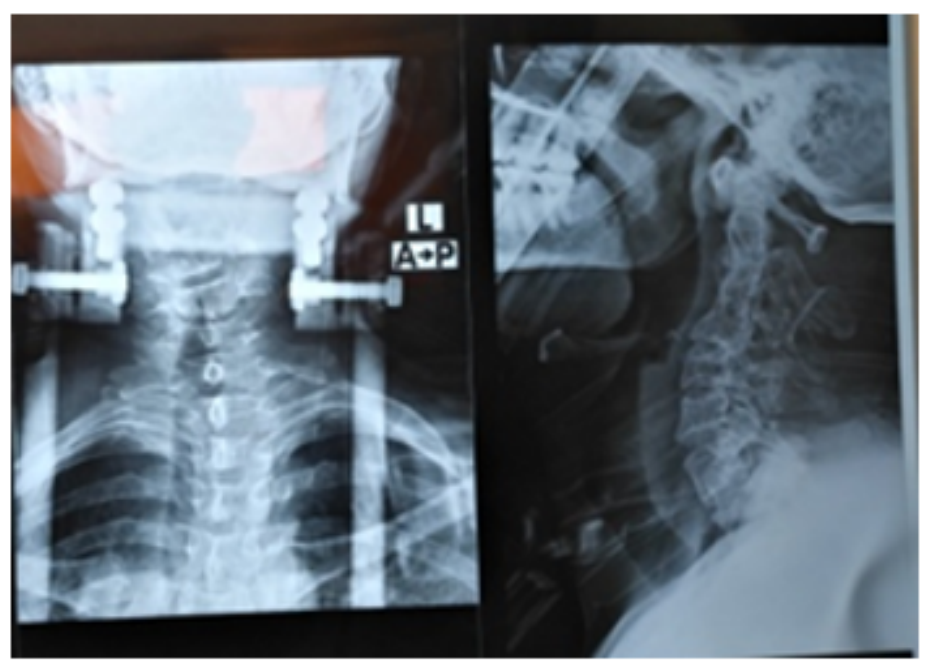

Figure 6

AP and L cervical X-RAY 8 weeks after application of noninvasive halo reveled healing odontoid fracture 

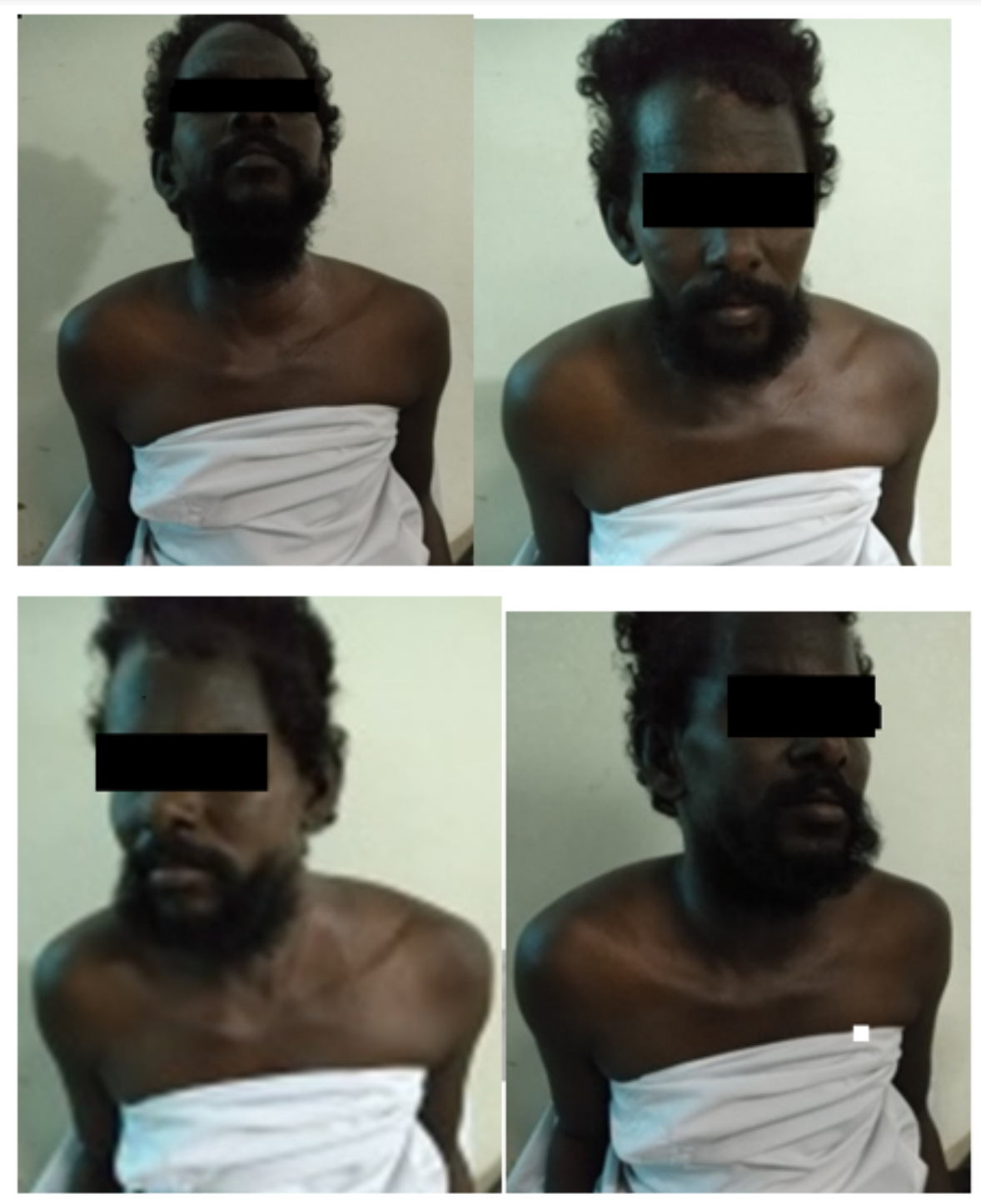

Figure 7

showed the patient immediately after removal of noninvasive halo, with initial restriction of ROM 